\title{
Application of Artificial Intelligence in Samsung - A Case Study
}

\author{
Sangeetha Prabhu ${ }^{1}$, \& Subrahmanya Bhat ${ }^{2}$ \\ ${ }^{1}$ Research Scholar, College of Computer Science and Information Science, Srinivas \\ University, Mangalore, India. \\ Orcid ID: 0000-0002-8026-1133; E-mail: sangeethaprabhu.ccis@srinivasuniversity.edu.in \\ ${ }^{2}$ College of Computer Science and Information Science, Srinivas University, Mangalore, India. \\ Orcid ID: 0000-0003-2925-1834; E-mail: itsbhat@gmail.com
}

Area of the Paper: Information Technology.

Type of the Paper: Research Case Study.

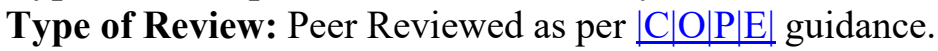

Indexed In: OpenAIRE.

DOI: $\underline{\text { http://doi.org/10.5281/zenodo.4427264 }}$

Google Scholar Citation: IJCSBE.

\section{How to Cite this Paper:}

Prabhu, Sangeetha, \& Bhat, Subrahmanya, (2020). Application of Artificial Intelligence in Samsung - A Case Study. International Journal of Case Studies in Business, IT, and Education (IJCSBE), 4(2), 280-292. DOI: http://doi.org/10.5281/zenodo.4427264.

International Journal of Case Studies in Business, IT and Education (IJCSBE) A Refereed International Journal of Srinivas University, India.

(C) With Authors.

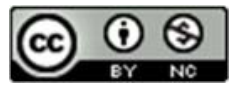

This work is licensed under a Creative Commons Attribution Non-Commercial 4.0 International License subject to proper citation to the publication source of the work.

Disclaimer: The scholarly papers as reviewed and published by the Srinivas Publications (S.P.), India are the views and opinions of their respective authors and are not the views or opinions of the S.P. The S.P. disclaims of any harm or loss caused due to the published content to any party. 


\title{
Application of Artificial Intelligence in Samsung - A Case Study
}

\author{
Sangeetha Prabhu ${ }^{1}$, \& Subrahmanya Bhat ${ }^{2}$ \\ ${ }^{1}$ Research Scholar, College of Computer Science and Information Science, Srinivas \\ University, Mangalore, India. \\ Orcid ID: 0000-0002-8026-1133; E-mail: sangeethaprabhu.ccis@srinivasuniversity.edu.in \\ ${ }^{2}$ College of Computer Science and Information Science, Srinivas University, Mangalore, India. \\ Orcid ID: 0000-0003-2925-1834; E-mail: itsbhat@gmail.com
}

\begin{abstract}
The global quest for issues with Artificial Intelligence (AI) is in a crisis point and the rewards are great. AI tech is expected to rapidly become a lifestyle for many consumers by everyday interactions with a digital assistant or personalized IT offering solutions based on a client's visual, tactile, or emotional signals. Samsung has been in a fantastic position to turn the future of connected AI technology into reality, from various electronic devices to $5 \mathrm{G}$ hardware to strong chipsets, based on roughly half the billion products sold by the company per year. Samsung works with a vision that says "By dedicating our technologies and expertise to support a broader international world, we create superior services and goods." Looking to be a global leader that evolves alongside people and local communities. Samsung It is the largest multinational corporation in South Korea, and is made up of various firms, several of which are named after Samsung. Lee Byung-Chul founded Samsung as a commercial enterprise in 1938. The company expanded into food processing, apparel, insurance, shares and delivery sectors over the next 30 years. In the 1960s and the mid-1970s Samsung enters the electronics and construction industries; those industries would result in further growth. Within this paper, highlight their technological histories and list Samsung's implementations, financial plans, market challenges and products. We tried examining about various fields where artificial intelligence is used, such as Bixby to facilitate smartphone connectivity with the Galaxy S8 Samsung smartphone, in the $8 \mathrm{~K}$ TV system we used a machine learning technique to improve image quality, walking robot's vertical approach allowed Saram to navigate and cross many surfaces.
\end{abstract}

Keywords: Samsung, Artificial Intelligence, Technology, IT industry, Electronics

\section{INTRODUCTION :}

Samsung has clearly been one of the world's most prominent companies for computerized equipment, appliances and semiconductors, storage and framework integration since its establishment as a small manufacturing company in Taegu, Korea. Samsung's creative and high-quality technologies and processes are now used worldwide. Established in South Korea in 1938In 1997, the company has earned more than 100 billion dollars in revenue annually from a startup business to a global [1]. Three global industries-electronics, telecommunications, and chemicals-Samsung operates and hires staff in over 60 cities. The corporate strategy is to devote human intelligence and telecommunications to the development of a new world by continuously developing services and goods. As for Samsung's brand, Samsung's confidence is based on how it's done across all Samsung devices recently. Problems with the goods had been marginal. Yet Samsung's cell phones have gained a status symbol for its consumers. Samsung's service is now being set up and people know that Samsung has a quick service for all of its products [2]. However, the premium range is now one of the main assets of Samsung's mix of advertisements.

Artificial Intelligence is an intellectual capacity displayed by machines instead of based on humans and other animals. It's like a machine that replicates what humans usually do, including fixing issues and learning. Every business must advance in this field, because every corporation has a product of its own, which is a helper that provides human support. It uses technologies well and is connected with network and gives 
consumers useful information. Siri, Google Allo and Bixby are included in these product lines, etc. There are also plenty of goods from other companies Market-available. These aids use artificial knowledge methods to enable the user to gather appropriate data or carry out the needed work.

There are no widespread contexts for using assistance. It is applied to robots or appliances which can recognize the requirements and take necessary actions. We can get the estimated costs of travel in Ola, Uber, Lyft, and several vehicle transportation services with the help of artificial intelligence alone. Now we've got home appliances like Alexa, Homepod, Home, etc. when incorporated with Internet of things, it provides the ability to follow up several activities in combination with pre-installed tools like theatre, monitors and displays. Some businesses are collaborating in this venture with external companies such as Philips, Samsung, who will support them link tubes with the residential care machine. One can also use this system anyplace. They will keep us safe and protected in the way that we might not have imagined in recent years, so it will conveniently have significant exposure to our enabled computer.

\subsection{Mission and vision:}

The mission statement of the company is "To enrich the lives as well as social obligations of people, to contribute to the sustainable society of advanced technologies, products and the ambition to design inspiration for the society of the future." That is the firm's belief that putting business together with Samsung's dream and target will allow Samsung to thrive in the market, retain its brand value and accomplish the world's best-five brand in 2020 .

\section{OBJECTIVES OF STUDY :}

This is a case study report based on data obtained from the Samsung business models in the area of artificial intelligence innovation [2]. The report addresses the following goals and objectives:

(1) To study the development story line for Samsung.

(2) Read the service levels and business plans among Samsung's biggest global IT firms.

(3) Determining the various devices where Samsung used Artificial Intelligence.

(4) Learn about Samsung's strategy for addressing problems with the Artificial Intelligence Platform.

(5) To know about Samsung's corporate social responsibility (CSR) activities.

(6) To suggest future success plans for Samsung SWOT analysis used.

\section{JOURNEY OF SUCCESS :}

- 1938-1970:

In the neighboring town of Daegu in 1938, Lee Byung - chul of the main landowners' community established Samsung Sanghoe, as just a small trading business with 40 employees Samsung began in Su-dong [3]. In 1947, Lee succeeded and moved his headquarters to Seoul. He began a sugar mill in Cheil Jedang, Busan. In different areas Samsung diversified. Lee tried to make Samsung a pioneer in various industries. Samsung switched to business lines such as banking, securities and distribution. The Hyosung group's founding member, Cho Hong-jai, jointly founded with Lee Byung-chull, chief of Samsung in 1947 in the new organization called Samsung Trading Company. Today the Samsung C\&T Company is the trading firm. Within a few years, the management style of Cho and Lee split. The Samsung Group was divided between Hankook Tire, Hyosung and Samsung and other businesses. The Samsung Company was introduced into the electronics business in the 1960s. They have developed and run several units relevant to the automotive industry, including Samsung Corning and ElectroMechanics, Electronics Systems, and Semiconductor and Telecommunications. The black and white TV was his first venture.

\section{- 1970-1990:}

The 1982 SPC-1000 was the first personal system for Samsung, and was used to store and load data on an audio cassette tape - the floppy drive was an alternative. In 1980, Samsung took the Hanguk Jeonja Tongsin, which was located in Gumi. The switchboards were his early inventions. The plant was the distribution base of Samsung's handheld production systems for phone and fax. To date, more than 800 million mobile devices have been made. In the 1980s it was listed under Samsung Electronics. Samsung Electronics, a corporation that was vital to the world's leader in technology, started to invest extensively in research and innovation in the 1980s. The TV assembly station was built in Portugal in 1982, the New York plant was built in 1984, the Tokyo plant was built in 1985, the England facility was built in 1987 [3]. In 1996, the other facility was built in Austin, Texas. Samsung invested in Austin, which is 
run under the Samsung Austin Semiconductor brand, for $\$ 13$ million in 2012. This makes the position at Austin some of Texas' most significant domestic investment, one of America's biggest single foreign investments.

- 1990-2000:

Samsung started to grow as a multinational organization in the 1990s. Samsung's advancement of architecture was an honor for one of the 2 Petronas tower buildings in Malaysia, Burj Khalifa in the UAE and Taipei 101 in Taiwan. In 1993, Lee Kun-hee auctioned 10 Samsung Group divisions and reduced their share and merged other operations in 3 sectors: telecom, engineering and chemical products [3]. Samsung became world's biggest memory chip manufacturer in 1992 and is the second biggest chip manufacturer in the world after Intel. The first display of liquid crystal was built in 1995 . Decade later, Samsung has become the leading global manufacturer of liquid crystal panels. In 2006, Sony developed S-LCD as the joint Samsung-Sony collaboration to provide both enterprises with reliability in the delivery of LCD screens, without investing in large TFT-LCDs [3]. S-LCD is owned and managed by Samsung in Tanjung and Sony in South Korea. It was revealed that Samsung had purchased Sony's interest in this joint venture by December 26, 2011. Samsung survived comparatively unharmed the Asian financial crisis of 1997 of contrast to the other big Korean firms. Nevertheless, Samsung's engine was significantly lost to Renault. Renault Samsung owns 80.1 percent of Renault as of 2010, while it holds 19.9 percent of it. Samsung has developed many planes, beginning in the 1980s and finishing in the 1990s. The company was founded in 1999 under the logo Korea Aviation Industry. The alliance was made among 3 major internal airspace units of Daewoo Heavy Industries, Samsung Aerospace, Aircraft and Hyundai Space [3]. Samsung also makes generators and gas turbines for aircraft.

\section{- 2000-Present:}

A center of development was opened by Samsung in Warsaw, Poland in 2000. The work began with the electronics of set-top boxes before expanding into wireless smart phones and television. The mobile platform was designed and introduced in 2008 with collaborators officially using the initial device line from Samsung Solstice as well as other versions and later became a Galaxy line of smart phones from Samsung including Note, Edge and other brands. A ten-year growth plan focusing on 5 companies was revealed in 2010. All of these firms were to concentrate on biopharmaceutical goods of which $2,100,000,000,000$ have pledged. In the first half of 2012, the world's top cell phone supplier, Samsung Electronics, overtook Nokia, an industry leader since 1998. On 24 August 2012, 9 U.S. jurors held Samsung Electronics liable for owing Apple $\$ 1.05$ billion in penalties for the violation of 6 of its mobile patents. The price also dropped under 2.5 billion dollars from Apple. It also claimed that Apple did not violate on the 5 Samsung patents listed in this case. Announced that step could be harmful to creativity in the industry. A South Korean decision was also released alleging that both firms were guilty of breaching intellectual rights of each other. Samsung's Kospi Index shares decreased in initial trade after the ruling to 1,177,000 Koreans, 7.7 percent; the highest loss in 24th of October 2008.

In 2015, Samsung earned a larger number of US patents than most other companies - like Sony, Google, IBM, Microsoft, and Apple - and was eventually asked to ban the sale of 8 Samsung phones [3]. By December 11, the company was granted 7,679 utility patents. The company issued 7,679 functionality patents by 11 December on 2 August 2016. The Galaxy Note7 cell phone, which was soldered on August 19, 2016, was launched by Samsung Electronics on August 2, 2016. Nevertheless, Samsung halted mobile services and declared an informal call back at the beginning of September 2016. This occurred because some telephone systems had faulty batteries, causing unnecessary heat, resulting in fires and blasts. This is, however, found to be a battery failure for the current edition of Galaxy Note 7, with Samsung modified recently reported telephone devices. Samsung recalled Galaxy Note 7 smartphones from all over the globe on 10 October 2016 and ended the production of the device the next day.

\section{FINANCIAL STATEMENT :}

Table 1 [3-9] gives a historical overview of financial affairs from 2014 to 2018 for Samsung over the past 5 years and graphically seen in figure 1 . 
International Journal of Case Studies in Business, IT, and Education (IJCSBE), ISSN: 2581-6942, Vol. 4, No. 2, December 2020

Table 1: Last five years Financial Statement

\begin{tabular}{|l|l|l|l|l|l|}
\hline Financial Statement & $\mathbf{2 0 1 8}$ & $\mathbf{2 0 1 7}$ & $\mathbf{2 0 1 6}$ & $\mathbf{2 0 1 5}$ & $\mathbf{2 0 1 4}$ \\
\hline Revenue & 243.8 & 239.6 & 201.9 & 200.7 & 206.2 \\
\hline Gross profit & 111.4 & 110.3 & 81.6 & 77.2 & 77.9 \\
\hline Operating profit & 58.9 & 53.6 & 29.2 & 26.4 & 25.0 \\
\hline Profit before income tax & 61.2 & 56.2 & 30.7 & 26.0 & 27.9 \\
\hline Net profit & 44.3 & 42.2 & 22.7 & 19.1 & 23.4 \\
\hline Revenue by Segment & & & & & \\
\hline SEMI & 86.3 & 74.3 & 51.2 & 47.6 & 39.7 \\
\hline DP & 32.5 & 34.5 & 26.9 & 27.5 & 25.7 \\
\hline IM & 100.7 & 106.7 & 100.3 & 103.6 & 111.8 \\
\hline CE & 42.1 & 44.6 & 44.7 & 44.8 & 50.2 \\
\hline Harman & 8.8 & 7.1 & N/A & N/A & N/A \\
\hline Operating profit by Segment & & & & & \\
\hline SEMI & 44.6 & 35.2 & 13.6 & 12.8 & 8.8 \\
\hline DP & 2.6 & 5.4 & 2.2 & 2.3 & 0.7 \\
\hline IM & 10.2 & 11.8 & 10.8 & 10.1 & 14.6 \\
\hline CE & 2.0 & 1.8 & 2.9 & 1.4 & 1.2 \\
\hline Harman & 0.2 & 0.1 & N/A & N/A & N/A \\
\hline Operating margin by Segment & & & & & \\
\hline Total & 24.2 & 22.4 & 14.5 & 13.2 & 12.1 \\
\hline SEMI & 51.7 & 47.4 & 26.6 & 26.9 & 22.1 \\
\hline DP & 8.1 & 15.7 & 8.3 & 8.4 & 2.6 \\
\hline IM & 10.1 & 11.1 & 10.8 & 9.8 & 13.0 \\
\hline CE & 4.8 & 3.7 & 5.6 & 2.7 & 2.4 \\
\hline Harman & 1.8 & 0.8 & N/A & N/A & N/A \\
\hline Regional portion of the Revenue & 18 & & & 10 & \\
\hline Domestic & 17 & 13 & 10 & 10 & 10 \\
\hline America & 34 & 34 & 34 & 33 \\
\hline Europe & 19 & 19 & 19 & 21 \\
\hline Asia/Africa & 18 & 19 & 21 & 20 \\
\hline China & & 18 & 15 & 16 \\
\hline
\end{tabular}




\section{Income Statement}

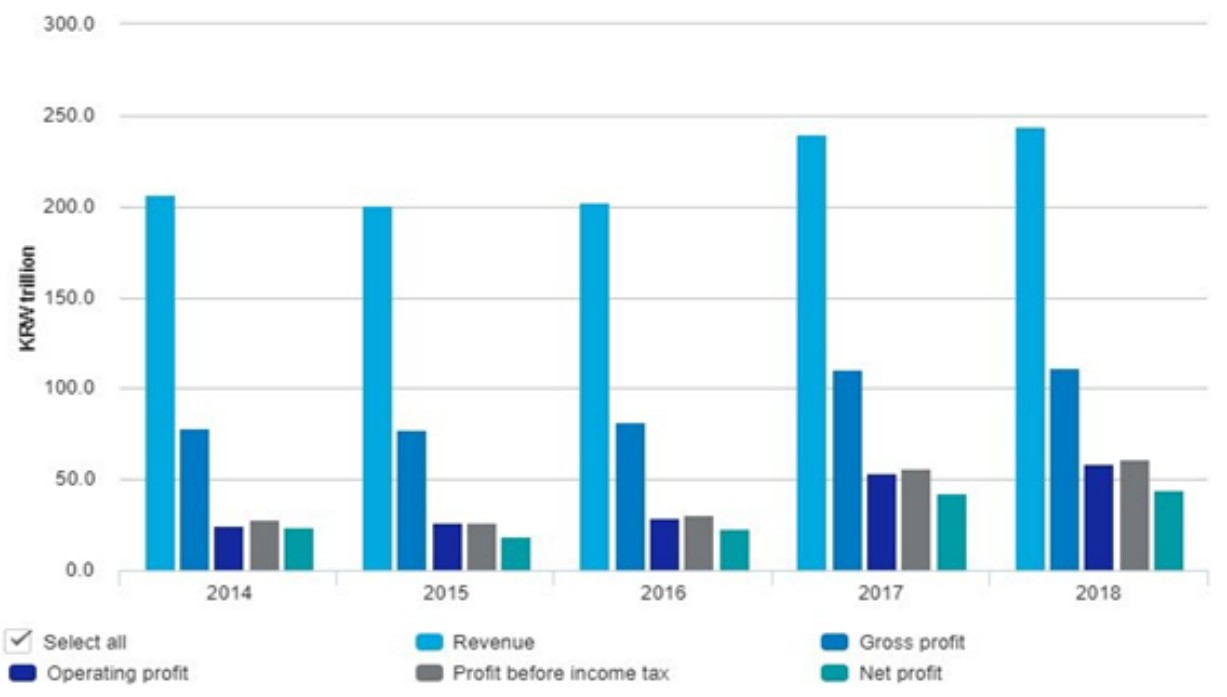

Fig. 1: Samsung's financial statement

\section{ARTIFICIAL INTELLIGENCE TECHNOLOGY IN SAMSUNG :}

The global search for AI is at high pace, and companies have a big stake. AI is supposed to become another lifestyle choice, with regular experiences with a modish-speaker or a customized AI that offers insights of visual, physical and subjective signals derived of a customer in the near future. In most social and economic sectors, AI will also be the greatest competitive enabler. Samsung is unique in its position to revitalize this world of interconnected AI services with almost half a billion devices sold every year, from different electronic products to effective chipsets, up to $5 \mathrm{G}$ instruments. In recent years, Samsung has investigated and effectively delivers goods and creativity to its global customer's lifestyle habits. A new era of connected life, impacting the consumer experience and the entire enterprise via AI, wasn't in this regard a technical business best known as Samsung.

The AI that Samsung adopts is available at all times, everywhere and is always developing to assist with the objective of creating value. To fulfill its goals, Samsung work explores the future generation AI technology to extend to all services and products. In addition, the main goal is to acquire cuttingedge core AI technology and networks-human AI capable of communicating, accepting and learning and provide its clients with fresh AI-based insight and value. A total of 7 AI centers worldwide are built in 5 countries: Korea (Seoul), Canada (Montreal and Toronto), Moscow, UK (Cambridge) and US (New York and Silicon Valley) by Samsung Research center. Via their unique regional abilities, they put Samsung's AI science and integrate AI technologies, products and services from these centers. The research in Samsung is expected to enlarge AI centers to include a range of other technological and talented areas to further strengthen its position as a market leader in IA research. Samsung Electronics, as one of the world's largest technology firms, is dedicated to creating outstanding goods and services and contributing to society. Samsung's mission is to create, link and deliver AI services through its vast product range, to support the entire humanity, both uniformly and globally. The company has committed to creating user-focused AI services and products focused on its "User-Centric," "Always there," "Always Helpful," "Always safe," "Always learning" and "Always Learning" AI vision.

\subsection{On-device artificial intelligence technology:}

In addition, last year Samsung developed and revamped the proprietary architecture of NPU applications. In addition, the Computer Visualization and Pattern Recognition (CVPR) business has released the integrated AI software platform. Samsung has shown promise in its lightweight On-Device AI technology that performs 8 times more complicated calculations than this 32-bit deep cloud-testing dataset [4-6]. The capability to measure high-speed data in huge quantities without electrical consumption is one of the main features of AI software on the device. 


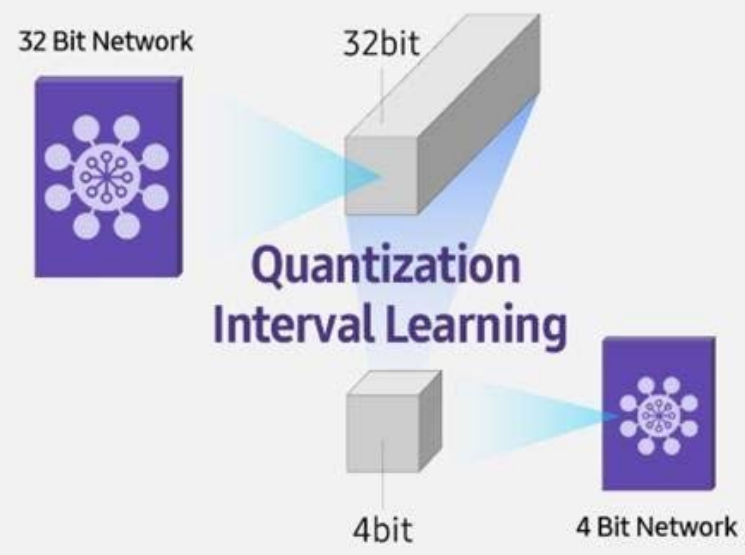

Fig. 2: On device AI Technology Network compression

The app describes consistent data sequences that influence deep learning performance by learning and says that the work conducted by Samsung Advanced Institute for Technology (SAIT) effectively shows how the in-memory deep learning system quantization at 32-bit cycles provides greater precision than many other current technologies when using memory. The output of the QIL approach is close to current implementations, although deep learning knowledge is given in bits of less than 4-bit clusters of 1/40 to $1 / 120$ fewer transistors. In comparison to arithmetical calculations [5], 'AND' and 'OR' doors are required. The cost of AI cloud technology for service alone can be minimized by smartphone apps, which provide reasonable and accurate performance for applications such as virtual reality and electric vehicles.

\subsection{Bixby:}

Bixby has been introduced, Samsung's Artificial Intelligence Platform to facilitate smartphone connectivity with the Galaxy S8 Samsung smartphone. Bixby 2.0 provides an AI system that can be compatible for all TVs, fridges, notebooks and other electronic wired devices [5]. The new update 2.0 offers "fast advancement to online assistance," and users will regularly communicate with numerous other goods and services. Bixby is familiar with natural language and helps users to communicate with systems that become highly complicated. Samsung deals with the Bixby support to Amazon Alexa and Google Home. The Bixby second gen model was introduced by Samsung during 2017. Bixby 2.0 appears to be "a foundational line of interactive assistants" and "an audacious interface reinterpretation," by the product. Bixby 2.0 was prepared for all phones by Bixby. Bixby 2.0 is free so that programmers can incorporate the software assistance into their apps and pick the way they communicate. For mobile phones, both Galaxy Note 8, S8 \& S8+, S9 \& S9+ can be used with Bixby. Samsung extends the AI assistant across different products from TVs to kitchen appliances. For the first time, Samsung launched a new Bixby driven frontload-washing machine in January 2019. Samsung has a Bixby app for Galaxy Home. Many other firms, although similar to Microsoft's Cortana, are not yet in operation to launch Bixby-based stereo headsets. The smart speakers of Alexa \& Google Assistant are now available.

\subsection{Samsung will add artificial intelligence to every device:}

Samsung reported at CES 2018 that maybe any product produced by 2020 will contain the skills of artificial intelligence. To ease control and tracking of the handset, the mobile service is merged into a new Smart things app. All Samsung devices not only will be eligible for the Internet of Things, they will also be equipped with AI by 2020. The main business strategies of Samsung tend to be AI \& machine learning.

\subsection{The machine learning to upgrade images:}

The first to release the $8 \mathrm{~K}$ AI TV system was Samsung Electronics. The system automatically processes content and increases the minimum picture quality resolution to $8 \mathrm{~K}[6]$. Through downloading highresolution material on a super high-resolution display, the breakthrough fixes the current problem [6]. You can also upgrade the videos to $8 \mathrm{~K}$, the highest optical television resolution today. 


\subsection{AI robot:}

Saram, a humanoid robot now designed under AI [7], is a new invention of Samsung Electronics. In his own factory, Samsung used the AI robotic arm technology to date, but experts predict that the firm will sell the robots although it is still completed. Sources also verified that Samsung's walking robot's vertical approach allows Saram to navigate and cross many surfaces. Considering success in other robotic industries and the fact that robots are Samsung's long-term development effort, it seems like Samsung will unleash its industrial robot in good time. With its success and efficiency for iOS, smartphone and home appliances, and previous AI encounters, Samsung's' vigorous contribution to AI growth and innovation aims to fill this void in the quest to prepare for the quarrian industrialization, including big data technology and the artificial intestines.

\section{PILLARS OF SAMSUNG'S BUSINESS STRATEGY :}

The business strategy of Samsung is highly scalable so that, based on changes in an ongoing business setting, the company can dramatically alter its approach. Few recognized that Samsung began as a grocery shop in Korea in 1938, changed into a noodle company in 1940 and moved into sugar production in 1950. In 1954 entered Woolen Company, and in 1956, the company of insurance and securities. As the first technical device, Samsung developed in 1960, black and white TV has since become one of the world industry leaders in electronics and technology. A constant change in direction and production of new products remains important characteristics of Samsung's market strategy.

Samsung's business plan consists of 3 components: a strong readership in the industry.

1. Efficient market user base: A business viewer company is being characterized as an entity that watches market trends and recreates innovative brands easily or provides new functionality on existing models that were originally launched by other firms. In particular, Samsung's architecture and essential features from its major rival, Apple, have proven successful in replicating. It was found that "an internally published 2010 by Samsung presented Samsung engineers with a step-bystep method for attempting to steal much of what rendered the iPhone such a special device".

2. Business prospects for testing and using: The corporate approach of Samsung involve a steady hunt for market prospects and uses the effectiveness of the proposed technique with good outcomes. For example, Samsung discovered that Asian performers required an appliance where they would write by hand, so it is simpler to play characters via pen. The outcome was a series of Samsung's Note devices produced as phone/tablet mixture ("pamlet"), which was an unexpected success.

3. New product development: With hundreds of varieties of products, Samsung Electronics has a broad product portfolio organized through 3 industry divisions: Consumer Electronics, Device Solutions, and IT \& Mobile Communications. In 2015, the global electronics company has 36 R\&D centers worldwide that ensure the stable future of core technologies. In 2006, Samsung becomes America's second biggest proprietor of patents. Product development skills have also been widely described as one of the key pillars of Samsung's strategic advantage.

\section{SAMSUNG CORPORATE SOCIAL RESPONSIBILITY :}

The implementation initiatives of Corporate Social Responsibility are applied via the Sustainability Advisory Board, which covers 14 of divisions involved and tackles concerns from 10 different fields, ranging from the environment and community. The central principles of Samsung's universal ethical codes are:

1. Maintenance of healthy organization,

2. Respect for customers, employees and other stakeholders

3. Environmental, health \& security

4. Being a socially responsible entrepreneur

The corporate perspective of CSR is administered by the Samsung Board committees. The company publishes annual status updates on Supplier Accountability and it includes information on the company's CSR initiatives and programs. Samsung Electronics deals with the aspects of business of CSR in 4 directions: health and safety, social donations, development sharing and green management.

\subsection{Samsung funds local agencies}

1. By relevant vocational training Samsung Tech Academy provides incredible autonomy and independence. The service was run by 39,659 recipients by end 2015 . 
2. By the ideal educational environment for the disadvantageous people SMART School bridges a big gap in education system. 224,753 learners had participated in 2015 in the SMART School.

3. Samsung Solve for Tomorrow is a program aimed at tackling important social problems. The curriculum involves children and charitable organizations who identify and pursue strategies to the most urgent environmental problems.

4. Samsung Care Drive enhances various health-care programs to handle technology assistance. In Chinese, Russia and other African nations, the organization had an aggressive frequency control of 30 in 201.

5. The objective of Samsung Nanum Town is to target poverty origins by providing economically deprived portions of society with an efficient infrastructure. Partnerships are being established with governments within the framework of this initiative to provide comprehensive funding for educational services, medical facilities, clean drinking water and public library construction.

6. The total number of Samsung volunteering hours during 2014 was $11.3 \mathrm{~h}$.

7. In 2015, Samsung set up the 6th Korean Hope House to enhance the circumstances of regional children's facilities.

\subsection{Educating and empowering workers:}

1. Employee benefits offered in 2015 totalled KRW 3,853 billion in Korea and abroad.

2. In 2015, the training time for every employee was $78 \mathrm{~h}$.

3. 5,500 people used Samsung Job Consultation Centre.

4. Samsung directs its yearly STaR trainings along with their EDP. It is a tool that allows people to prepare workers plan a specific career choice with their boss and develop a shared vision. Every year 2000 staff members in Korea alone undergo STAR sessions.

\subsection{Employee health and safety at Samsung:}

1. Samsung prioritizes the creation of health and safety management. The business follows the OHSAS 18001 requirement for occupational safety and health management programs in its workplaces worldwide.

2. Samsung is still seeking to run its workplaces in secure conditions. The organization has routinely carried out inspections and enhancement and also organizes periodic cases of crisis for leaks of hazardous chemical products, burns, accidents and natural disasters.

3. Samsung promotes workplace safety and well-being through the development of ergonomic workplace software and the prohibition of business trips to regions of strong threat of bacterial infections Ebola and MERS, for instance.

\subsection{Samsung waste drop and reprocessing:}

1. Samsung has collected 2.26 million tons of trash from 2009 to 2015 , with a goal of collecting 3.8 million tons of waste by the year 2020 .

2. In 2015, an average of 34,322 tons of biodegradable materials were deployed for computers, fridges, filters, vacuum cleaners, presses and headset boxes ( 6.3 percent of global plastics uses).

\subsection{Samsung's greenhouse emissions:}

1. Greenhouse gas emissions have fallen by $70 \%$ under Samsung's Eco-Management 2020 and World First programs, and since 2008, greenhouse emissions were 250 million tons.

2. Environmental communication programs aimed at spreading Samsung Environmental Management's interest have launched numerous transparent initiatives across the globe. This included courses and events on environmental education, and supporting employee aspirations in participating in such events.

3. The company runs green work environments by reducing carbon emissions and water use, and by increasing recycling rate at its office buildings.

4. Over the period from 2009-15, Samsung accomplished an overall cumulative reduction in product consumption of 156 million tons of greenhouse effect.

\subsection{The competitive procurement of Samsung:}

1. Samsung sustain Distributor Consultancy Team, which includes a roster of 100 managers and directors in the production, product, growth and Sectors for quality management 
2. The company runs a KRW 1 trillion to help suppliers boost business who finds it difficult to secure funding.

3. An effort to establish a win-win relationship with suppliers is the 7 Joint Growth Implementation Strategy launched in 2010. The Samsung-instituted Win-Win Partnership Academy helps its suppliers improve their businesses.

\section{SWOT ANALYSIS :}

Samsung Electronics Limited is the Samsung Corp., a corporation based primarily on the consumer electronics division, headquartered on Suwon, South Korea. Samsung's major cell telephone and laptop makers, including the wildly popular and famous Galaxy, are established in and around Korea and it is the world's biggest manufacturer of TV and LCD screens. .Samsung is known for its manufacturing and distribution success as the world's second biggest consumer electronics. SWOT review appears to be a valuable means of identifying your talents and shortcomings and understanding your prospects and arguments. What makes SWOT to be particularly strong is that it can help you exploit chances with thought. In addition, if you do not recognize the company's limits, you will handle risks that would otherwise make you unaffected [8]. So you and your rivals build a strategy that helps you differ from your competition, meaning that by looking at yourself and your rivals using the SWOT model you have influence in the market.

\subsection{Strengths:}

1. Samsung is a world-renowned manufacturer of electronics. This is also the largest worldwide maker of TV, LCDs, phones and notebooks.

2. Samsung had become world's leading smartphone marketing firm as in second half of 2015 with a profit margin of 21.4 million.

3. Samsung has the number two with an impressive architecture and development Volume of 19 million.

4. In less than a year, Samsung Pay could build and create an APP with the same features.

5. Samsung replicates the features of both Apple Inc. and Google Inc.'s Android OS system.

6. The development and delivery capabilities of Samsung are strong.

7. Samsung will manufacture and sell really well.

8. Samsung has long-standing relationships with US and European firms offering a profitable brand path.

\subsection{Weaknesses:}

1. The digital advertisement capability of Apple Inc. cannot be compatible with Samsung. U.S. mobile business shares declined by 2.3 million between 2014 and 2015. The share value of Apple is, however, increased by $34.9 \%$.

2. Most Chinese rivals seek to remain on a smartphone platform with Samsung. During 2014-15, Huawei's and Xiaomi's share improved by $48.1 \%$ and $29.4 \%$ respectively.

3. Samsung is reliant on exporting to countries with a substantial growth opportunity, including the United States and Europe, of consumer goods to a large degree.

4. Samsung phones use the open source operating system of Google Android.

5. Apple products are considered by some customers more mature and much more reliable than Samsung products.

6. Samsung is not as advanced as Apple's marketing tactics.

\subsection{Opportunities:}

1. The growing smartphone, tablet and other mobile industry, particularly in the wireless, tablet and other device industries, particularly in the developing economies, including Africa and India, where purchases of PCs are not satisfied.

2. In 2015, traditional device sales were steadily outstripped and surpassed.

3. Improved cell phone and tablet market, such as new portable devices from Samsung Pay.

4. The growth of the middle class in the developing world will boost the consumer market.

5. The online demand from sources like Amazon is rising.

\subsection{Threats:}

1. Apple continued to emerge as the leading phone and tablet brand in many countries, including the United States. Samsung's role is not to conquer Apple's corporate credibility. 
2. Apple appears to be dedicated coherence, consistency and sophistication.

3. Smartphones of Galaxy rely on Google's Android OS, which is less popular than the IOS.

4. Declined or diminished middle class revenue in North America and the United States, which restrict customer procurement power in the major Samsung markets.

5. The main rivals of Samsung will come from Chinese companies such as Xiaomi \& Huawei. The earnings in these companies have increased since Samsung drops.

6. Apple can reach competing markets for electronic goods such as home electronics, cameras and compete negotiate with Samsung in those sectors.

\section{CONCLUSION :}

Global corporate market competitiveness helps Samsung be more creative, not only in the company's goods and services, but also in its strategy and policies. Obviously, the success of Samsung owes it to the company to be innovative again. It is a positive and innovative contribution to the styles of senior management by encouraging people to take part and be involved. Its innovation was mainly in the company's people. Samsung regards them as a pivotal asset. Samsung aims at becoming global communications and electronics leader in all aspects of the industry. It needs training and offers incentives to employees. The vision of Samsung on Artificial Intelligence is to establish an environment, which allows users to connect effortlessly to get things accomplished through various devices and techniques. Devices of Artificial Intelligence make our work much more convenient. The device Bixby assist us to connect the smartphone especially Galaxy S8, implementation of ML technique lead to the quality of image in $8 \mathrm{~K} \mathrm{TV}$, the Saram is used for navigation purpose, etc. In this way the devices which used artificial intelligence, studies our routines, recalls what's essential to us and operates to accomplish tasks

\section{REFERENCES :}

[1] History of Samsung Retrieved from https://www.samsung.com/in/aboutsamsung/company/history/ on 09/12/2019.

[2] Marketing Mix of Samsung from https://www.coursehero.com/file/17849844/Marketing-mix-of-Samsung/ on 10/04/2020.

[3] Samsung Retrieved from https://populartimelines.com/timeline/Samsung on 10/04/2020.

[4] Technological Advancement at Samsung Retrieved from https://www.totalbusinessmagazine.com/2018/12/a-new-era-of-technological-advancement-atsamsung/ on 10/12/2019.

[5] Samsung's financial statement Retrieved from https://www.samsung.com/global/ir/financialinformation/financial-valuation-snapshot/ on 09/12/2019.

[6] The Amazing Ways Samsung Is Using Big Data and Artificial Intelligence Retrieved from https://bernardmarr.com/default.asp?contentID $=1697$ on 09/12/2019.

[7] Essays, UK. (November 2018). Technology and Innovation at Samsung. Retrieved from https://www.ukessays.com/essays/marketing/strategic-technology-and-innovation-at-samsungelectronics-marketing-essay.php?vref=1 on 09/12/2019.

[8] On device AI technology at Samsung Retrieved from https://analyticsindiamag.com/samsung-creates-on-device-lightweight-ai-technology-that-is-8times-faster/ on 09/12/2019.

[9] Samsung On-Device AI technology for AI Deep Learning Retrieved from https://www.fonearena.com/blog/286030/samsung-on-device-ai-technology-for-ai-deeplearning.html on 08/12/2019.

[10] Aithal, P. S. (2017). Company Analysis-The Beginning Step for Scholarly Research. International Journal of Case Studies in Business, IT and Education (IJCSBE), 1(1), 1-18.

[11] Aithal, P. S. (2017). ABCD Analysis as Research Methodology in Company Case Studies. International Journal of Management, Technology, and Social Sciences (IJMTS), 2(2), 
40-54.

[12] Aithal, P. S. (2017). Industry Analysis-The First Step in Business Management Scholarly Research. International Journal of Case Studies in Business, IT and Education (IJCSBE), 1(1), 113.

[13] Nofal, R., Calicioglu, C., \& Aljuhmani, H. Y. (2020). The impact of social networking sites advertisement on consumer purchasing decision: The Mediating role of brand awareness. International Journal of Data and Network Science, 4(1), 139-156.

[14] Chang, V., Zhang, W., \& Xiong, C. (2018). The Strategic View and Development of Corporate Social Responsibility. International Journal of Strategic Decision Sciences, 10(1), 105-130.

[15] Magnusson, P., Westjohn, S. A., \& Zdravkovic, S. (2011). "What? I thought Samsung was Japanese": Accurate or not, perceived country of origin matters. International Marketing Review, 28(5), 454-472.

[16] Leachman, R. C., Kang, J., \& Lin, V. (2002). SLIM: Short cycle time and low inventory in manufacturing at Samsung electronics. Interfaces, 32(1), 61-77.

[17] Baloh, P., Uthicke, K., \& Moon, G. (2008). A business process-oriented method of KM Solution design: A case study of Samsung Electronics. International Journal of Information Management, 28(5), 433-437.

[18] Moro, S., Pires, G., Rita, P., \& Cortez, P. (2020). A cross-cultural case study of consumers' communications about a new technological product. Journal of Business Research, 121(1), 438447.

[19] Omer, S. K. (2019). SWOT analysis implementation's significance on strategy planning Samsung mobile company as an example. Journal of Process Management. New Technologies, 7(1), 56-62.

[20] Lee, Y. W. (2019). Enhancing shared value and sustainability practices of global firms: The Case of samsung electronics. Strategic Change, 28(2), 139-145.

[21] Wilson, N., \& Makmud, S. T. (2018). Case Study of the Indonesian Smartphone Industry. Journal Muara Ilmu Sosial, Humaniora, Dan Seni, 2(2), 633-649.

[22] Lu, H., Li, Y., Chen, M., Kim, H., \& Serikawa, S. (2018). Brain Intelligence: Go beyond Artificial Intelligence. Mobile Networks and Applications, 23(2), 368-375.

[23] Almutairi, M., Mehta, S., Rashidi, F. Al, Villa, M. A., \& Anggawinata, F. (2019). Analysis of Samsung's internationalization process and the strategies implemented to generate an effective positioning of its brand and products in foreign markets. Journal of the Community Development in Asia, 2(1), 27-39.

[24] Kim, S. (2018). Developing the Strategies for AI Products based on the Technology Decomposition Framework, 2018 IEEE International Conference on Industrial Engineering and Engineering Management (IEEM), Bangkok, pp. 1250-1254.

[25] Kim, S., Lee, H., Kwon, Y., Yu, M. and Jo, H. (2016). Our Journey to Becoming Agile: Experiences With Agile Transformation in Samsung Electronics. 23rd Asia-Pacific Software Engineering Conference (APSEC), Hamilton, pp. 377-380.

[26] Abhishek, \& Garg, H. (2018). Samsung Electronics in India: Challenges of Multi-Channel Retailing. Asian Case Research Journal, 22(1), 87-111.

[27] Jang, S. H., Lee, S. M., Kim, T., \& Choi, D. (2019). Planting and harvesting innovation-an analysis of Samsung Electronics. International Journal of Quality Innovation, 5(7), 1-16.

[28] Han, Y. W. (2016). Case Note (2): Samsung Electronics Co., Ltd., et al. v Apple Inc. 137 S. Ct.429 (Dec. 6, 2016)-Overview of the design patent lawsuit between Samsung Apple. Northeast Asian Law Review, 10(1), 65-72.

[29] Sung, C., Kim, K. C., \& In, S. (2016). Cooperation Strategy in the Business Ecosystem and Its 
International Journal of Case Studies in Business, IT, and Education (IJCSBE), ISSN: 2581-6942, Vol. 4, No. 2, December 2020

Healthiness: Case of Win-Win Growth of Samsung Electronics and Partnering Companies. The Journal of Small Business Innovation, 19(4), 19-39.

[30] Iblasi, W. N., Bader, D. M., \& Al-Qreini, S. A. (2016). The impact of social media as a marketing tool on purchasing decisions (Case study on SAMSUNG for electrical home appliances). International Journal of Managerial Studies and Research, 4(1), 14-28.

[31] Haroun, I. M. (2016). Exploring Corporate Strategic Management and Global Expansion on the Case study of Samsung Electronics. Archives of Business Research, 4(1), 216-229.

[32] Abhishek, A., Baloh, P., Uthicke, K., Moon, G., Chang, V., Chen, S., Li, Z., C., Fu, X., Pradana, A., Sing, G. O., Makmud, S. T. (2019). The Uncertain Future of Artificial Intelligence. International Journal of Computer Information Systems and Industrial Management Applications, 2(1), 61-77. 